\title{
BENEFITS OF FREEWRITING FOR ACADEMIC STAFF ENGAGED IN A WRITING RETREAT
}

\author{
J. Castle \\ School of Education \\ University of the Witwatersrand \\ Johannesburg, South Africa \\ e-mail: jane.castle@wits.ac.za
}

\section{ABSTRACT}

Increasing pressures on academics, particularly early-career academics, to conduct research and complete higher degrees has led many institutions to offer writing retreats that focus on the end product of academic writing, typically a journal article based on a chapter of their thesis. These 'product-oriented' retreats give little attention to the creative processes involved in writing, including becoming a generative and confident writer. This article focuses on freewriting as a creative process in a 'process-oriented' writing retreat which enables the benefits of freewriting to be shared among participants. Analysis of three freewrites completed by academics during a retreat shows that focused freewriting can engage academics in re-imagining doctoral study. These academics' writing shows clearly the attributes and benefits of freewriting.

Keywords: freewriting; writing pedagogies; writing retreats; writing strategies; doctoral studies; academic staff

\section{INTRODUCTION}

Problematising the pedagogies that can be applied in writing retreats is a potentially useful way to help academic staff survive and thrive as writers in the current stressful university environment. In this article I propose that freewriting is a strategy that not only helps academics write freely and creatively; it also helps academics problematise their tacit and experiential knowledge, assisting them in recognising their own narratives and in considering alternatives. The ability to do this develops critical (self) awareness and critical reflection on different ways of being and doing. The capacity for critical thinking is one of the hallmarks of academic endeavour in all disciplines. In addition, I argue that the generative and enjoyable aspects of freewriting (Elbow 2000; Murray 2009) can be increased by making it a central pedagogical practice in a 'process-oriented' writing retreat.

Not only can freewriting help novice and experienced writers to reflect backwards and forwards on experience and capture their thoughts in writing; it can also assist them to activate or reframe their tacit knowledge in an easy and enjoyable way, thus reducing the anxiety that 
many writers experience (Murray 2013; Murray and Moore 2006). Exploring a group of doctoral students' reflections in hindsight about writing a thesis also has the potential to sensitize others, for example, other postgraduate students and supervisors, to some of their roles and practices.

Sharing their experiences by reading their freewrites aloud to one another, and listening to what others have to say, in the safe space of a process-oriented writing retreat, helps writers consider alternative ways of thinking, writing and being. Considering different ways of writing a thesis is a valuable process in itself. Freewriting, used as a central pedagogy in a writing retreat, can help academic staff to thrive as research writers in the stressful context of university life.

In this article I present three short, focused, reflections by academics about what they would do differently if they were starting a doctoral thesis again. The reflections are in the form of focused freewrites (Elbow 2000; Badenhorst 2007) completed by doctoral students who participated in a five-day, non-residential writing retreat designed to assist them to progress in their scholarly writing projects. The freewrites show that freewriting can elicit spontaneous, yet powerful, writing of interest and benefit to the writer and others.

\section{RESEARCH FOCUS}

In this article I focus on the benefits of freewriting for academic staff by first describing how free writing works, and then showing how it can be effective in a writing retreat that cultivates community and collegiality among academic staff, as well as creativity and reflection in writing. I begin by situating freewriting in doctoral writing, then positioning it as a central pedagogic strategy in a process-oriented writing retreat. I then illustrate the benefits of freewriting by analysing three short texts that academics wrote in response to the prompt: 'If I were starting my thesis again ...' I conclude the article by affirming the benefits of freewriting to academic writers engaged in doctoral studies. This article complements others in this special issue that explore writing pedagogies and writing retreats.

\section{CONCEPTUAL FRAMEWORK}

I begin this section with an account of the contextual pressures on academic staff who are also doctoral students to produce and produce (Harrison 2011). I then proceed to a discussion of writing as a method of enquiry, and freewriting as a pedagogical strategy and finally, I turn to the subject of writing retreats. 


\section{Doctoral students under pressure}

Burford (2014), writing about doctoral study in New Zealand, indicates that the ubiquitous culture of audit, scrutiny and precarious working conditions in higher education institutions is increasingly affecting students negatively. Citing the long hours, poor pay and poor prospects of promotion of academics generally, and the culture of managerialism, audit and 'metricization' that prevails in universities of the North and the South, Burford describes doctoral students as 'increasingly sore, stressed and feeling anxious and guilty’ $(2014,69)$. He urges supervisors and researchers to focus their attention on the 'messy, ordinary and emotional lives of students and the conditions under which they study, work and seek employment' (2014, 69). He also points to the changing role that writing and be(com)ing a writer plays in the lives of students $(2014,69)$. I suggest that the institutional and cultural changes facing doctoral students in South Africa in 2016 are similar to, if not harsher than, those Burford (2014) describes in the case of New Zealand.

A recent survey of doctoral supervisors in South Africa by Mouton, Boshoff and James (2015) sketched the broad characteristics of doctoral students in South Africa. They found that doctoral students are 'mature', at 41 years of age on average, and take about five years to complete a PhD. Unlike many doctoral students in the North, or in Australasia, students in South Africa can rarely access the funds to finance full-time study, so they register as part-time students while engaged in full-time employment. Progress on their studies is frequently delayed or interrupted by the competing demands of their families and employers (even when the employer is the academic institution at which they are studying). At the same time, doctoral students are under pressure to complete their degrees in minimum time so that their institutions and supervisors can reap financial and reputational rewards. All of this means that part-time study is something that South African students fit into evenings, weekends and occasional days off (Mouton et al. 2015). These characteristics of doctoral students, and the contextual pressures they face, resonate strongly with my own experience of undertaking a $\mathrm{PhD}$ as a member of the academic staff of a research university.

One-on-one supervision (rather than group or committee supervision) is the norm for students in the humanities and social sciences (Mouton et al. 2015). This mode of supervision is demanding for students and supervisors alike, particularly with the increase in student registrations that most academics in South African universities experience. Because most doctoral students are working full-time, a great deal of supervision is carried out by email or skype, requiring of both students and supervisors different resources and skills. Supervisors complain that students are poorly prepared for doctoral study, and that they 'cannot write 
scientifically', meaning that they do not know how to select relevant literature, and lack the skills to analyse data properly (Mouton et al. 2015, 3). All in all, it appears that doctoral students, like their supervisors, face overwhelming pressure to deliver results, in institutions that are unable to provide adequate support or resources. The ever-increasing pressures on academics motivated me to explore some of the ways in which writing strategies and pedagogies, such as freewriting and writing retreats, can help academic staff to become more creative, generative and confident writers.

\section{Writing as a method of enquiry}

As long ago as 2000, Richardson criticised the standard 'limiting', and 'objectifying' practices of social sciences research in the USA. She slated the 'mechanistic' method of 'writing up research' after collecting data $(2000,5)$. She called for writing, or the process of writing, to be recognised as 'evocative' - a way of investigating 'how we construct the world, ourselves and others' $(2000,5)$. She proposed that writing was a research practice, a method of discovery and analysis, as well as a creative practice (Richardson 1998). She maintained that knowing the self and knowing about the subject of enquiry were intertwined, and that having a partial, local, or historically situated knowledge 'is still knowing’ (Richardson 2000, 8). Richardson proposed that by writing in different ways, researchers could discover new aspects of their topic and their relationship to it. She saw writing as a creative and analytical process, valid as a method of knowing (2000).

For Richardson, the researcher is the instrument in qualitative research, rather than the interview, the survey or the questionnaire. The researcher's knowledge is situated in her 'voice' (Richardson 1998, 363). Experience and memory are open to interpretation, governed by social interests. We understand ourselves reflexively from particular positions at specific times. Thus form and content are nearly inseparable. Writing process and writing product are interconnected.

Like Richardson, Kamler $(2001,14)$ also rejects ‘mechanistic' and ‘objectifying’ methods of research and research writing. She affirms that research writing is a method of discovery - a dynamic and reactive process. Writing relocates the writer in relation to her writing. Writing prolifically, that is, with ease and confidence, requires letting go, being surprised, and even writing 'rubbish' (Kamler 2001, 13). I agree with Richardson and Kamler about the nature of research writing and writing prolifically. Later in this article, I propose that freewriting, especially with other writers in a retreat, is a process that helps writers to write with ease and confidence. 
Building on the contributions that Richardson (1998; 2000) and Kamler (2001) make about research writing, Badenhorst (2008) remarks that the process of writing a doctoral thesis is neither straightforward nor linear. Scholars find themselves working simultaneously on different sections, or chapters at different stages of completion. For example, in writing the research findings, a student may be trying out different techniques for representing the data, while revising the methodology chapter and adding material to the review of literature. Badenhorst (2008) proposes freewriting as a key technique in thesis writing, as it is simultaneously a way to work through problems and get words on the page.

\section{Freewriting}

The purpose of freewriting, as proposed by Richardson (1998; 2000) and Kamler (2001), is knowledge creating rather than knowledge recording. The basic principle is to write continuously and quickly, for an agreed period of time - for example, one or five or twenty minutes - without stopping (Elbow 2000; Goldberg 1986). The writer does not refer to external sources (books, journals, the Internet) or control her thinking. S/he does not stop to correct grammar or spelling; does not draw lines through text or rub out words; and, in fact, does not lift the pen from the page for the duration of the freewrite. Nor does s/he write for a particular reader or audience. Engaging in any of these editing activities could mean that the writer's internal scholar or editor was casting a critical eye over the work (Badenhorst 2008; Goldberg 1986). The principle is that, in order to write freely, to let the writing flow, it is necessary to suspend (editorial) judgement. The rapidity of freewriting means that the writer makes no conscious investment in the freewrite. The writer writes to see what s/he knows, thinks or feels about something. Relinquishing control in this way often releases surprising, original ideas and thoughts.

Elbow (2000, 86-87) describes two forms of freewriting. The first is a process of 'blurting out' 'first thoughts, musings and perplexities' about a topic. The writer captures her own ideas and thoughts in words. In blurting out, freewriting simply gets words on paper and breaks the barriers of uncertainty and the struggle to begin writing (Murray and Moore 2006; Badenhorst 2007). It helps writers overcome 'writer's block'. The second way of understanding freewriting is 'focused freewriting' exploring a particular topic or issue. As in blurting out, the non-stop writing process also helps the writer to get down what she knows about a topic. But Elbow (2000) also claims that focused freewriting improves thinking, and can lead to meta-discourse. Freewriting encourages dialogue with ourselves. Focused free writing leads the writer to identify what her dilemma is; why her ideas make sense or do not. We all have tacit and intuitive 
knowledge, as Richardson (1998; 2000) proposed. Through free writing, as Elbow (2000) points out, we can bring more of our tacit knowledge into words and into conscious awareness and then work with it.

Murray (2009) suggests that freewriting may be particularly helpful for novice writers, as it helps them generate ideas and possibilities, without evaluating them. 'You start to write, even if you are, in fact, unsure about where the writing is going' (2009, 93). Material for focused freewriting may include 'an accumulation of your experience, education, experiments, reading, worries, feelings, conversations and $1986(2009,96)$. She lists sixteen uses for freewriting, including thinking about both sides of an issue; thinking through alternatives to one's own view; breaking through rigid or established ideas; 'ventilating' feelings and ideas; and expressing first thoughts and impressions.

For Elbow (2000), Goldberg (1986), Badenhorst (2007, 2008) and Murray (2009), freewriting is a process rather than a product. Elbow (2000) claims that freewriting removes most of the risks and constraints involved in academic writing. By removing self-imposed constraints, for example, to always write perfectly and fluently, freewriting puts life into writing by allowing voice, energy and presence to emerge. Writers begin to 'speak' on paper (Elbow 2000, 86). Further, when writers regularly do freewriting, they obtain satisfaction and pleasure from it. Writing becomes an occasion of discovery rather than drudgery.

So, in summary, according to Elbow (2000), Goldberg (1986) and Badenhorst (2007), freewriting releases ideas and thoughts to flow and to be gathered. It gets words on paper. It improves thinking. It is enjoyable. It is also a strategy for capturing and extending the writer's voice (Richardson 2000).

The unstructured nature of freewriting can be a challenge for researchers who have been taught that writing is an activity that comes after research, that is, after reading, thinking and data analysis. Such researchers might protest that they have nothing to say, or that they are not yet ready to write (Murray 2009, 93). They believe that 'writing up' is an end-product of research, conducted according to strict disciplinary norms. For writers who hold this belief, writing is not an integral, dynamic or creative part of research; it is simply a medium for recording or reporting research.

Some research writers, especially those in the physical sciences, would argue that academic writing must conform to implicit disciplinary or professional conventions, for example, that the writer is invisible, objective and has no voice (Richardson 2000). Academic language and academic writing sustain the exclusivity and authority of disciplinary discourse, distinguishing between those who understand it and those who do not (Badenhorst, Moloney, 
Dyer, Rosales and Murray 2015). For these reasons, some academics mistakenly perceive the creative, playful aspects of freewriting as childish or purposeless. They might charge that freewriting is whimsical, or unfocused, or flimsy - a waste of time. In response to these charges, Elbow (2000), Richardson (2000), Badenhorst (2007) and Murray (2009) marshal a strong defence of freewriting. They would argue, first of all, that writing conventions and standards are not fixed, but change over time; that research genres are becoming blurred (Badenhorst 2007). There is no 'one right way to write', as Richardson (1998; 2000) pointed out. The relationship between scientific and literary writing has become increasingly complex, especially in the humanities and social sciences (Badenhorst 2007). Secondly, writing a conference paper, an article or a thesis chapter is not something produced instantly according to a formula. It is a process which takes place in stages. The initial stage may include a variety of freewrites, sketches, thoughts, lists and mindmaps. Badenhorst (2008) calls this stage 'prewriting'. The next, and longer, stage is 'writing freely', in which the notes and ideas from the pre-writing stage are gathered and arranged into a more coherent and meaningful 'academic' form. The final stage is revising or editing. The stages are not discrete and linear, but rather iterative, or circular, possibly spiral-like.

Many of the ideas and concepts presented above suggest that writing with like-minded others, so that the benefits which accrue from freewriting can be shared, could prove valuable. A process-oriented writing retreat is an ideal place to do freewriting, as I show below.

\section{Writing retreats and writing pedagogy}

All writing retreats offer participants time and space for writing and to develop their writing. In their earlier work, Benvenuti, Castle and Keane (2013) described the process-oriented writing retreat as a type of retreat that provides a space and time protected from the incessant demands of the university, as described by Grant (2006). The process-oriented retreat provides a balance between the solitude needed to write, and the social benefits provided by a community of writers (Castle and Keane 2016a). It provides a series of opportunities to explore writing.

The structure of a process-oriented retreat is flexible; negotiated with participants who forward their ideas, interests, and goals to the facilitator in advance of, and during, the retreat. The values sustained in a process-oriented retreat, including harmony, collegiality, trust, creativity and transformation, are reflected in the retreat's pedagogy and structure, in which solitude and communal activities are interspersed. In Benvenuti et al. (2013) and Castle and Keane (2016b), the process-oriented retreat is linked to the concept and practices associated with academic literacies (Street 1984), and to the development of collegial and supportive 
relationships. It contrasts with the 'structured' or 'product-oriented' retreat (which is more like a course or workshop) in which students and academics are taught how to write journal articles and thesis chapters, under the banner of capacity building.

In a process-oriented writing retreat, the, participants sit around a large conference table with space for their notebooks, pens, laptops and other props. After freewriting for several minutes, instigated by a prompt devised by the facilitator, writers are invited to read their freewrites aloud to others, often in pairs or triads. The reading aloud process acknowledges and appreciates the diversity of voices and the quality of ideas produced by writers through freewriting, and also builds confidence among them, in their ability to generate meaningful text, quickly and easily. Reading aloud gives the writer distance from the experience of writing the text, and releases her from the intensity of her writing (Kamler 2001, 61). Writers take turns reading aloud and soliciting responses and critique from others.

Process-oriented writing retreats provide a favourable context for reflection and writing. They offer time away from work to think, read and write, in a pleasant ambience. They foster collegiality and mutual respect among writers, and pleasure in learning about, and from colleagues in other disciplines. This is in addition to any practices, strategies and skills developed during the retreat.

In the section above on freewriting, I showed that proponents of freewriting, such as Goldberg (1986), Elbow (2000) and Badenhorst (2008), indicate that freewriting has the potential to generate and gather original thoughts and ideas. It gets words on the page. It is quick, easy and enjoyable, and therefore eliminates writer's block, building confidence in the writer and her writing. I also suggested that freewriting, used in a group setting such as a writing retreat, could elicit authentic voices, lateral thinking and reflection, both forward and backward moving. I propose next to provide evidence for these claims by presenting and analysing three freewrites produced by doctoral students in a process-oriented writing retreat, but before that, I will present the research design and process.

\section{RESEARCH DESIGN AND PROCESS}

\section{Context and participants}

The writing retreat described in this article was one of 27 retreats that a colleague and I had designed and facilitated for academic staff of the University of the Witwatersrand between 2011 and 2015 (Castle and Keane 2016a). Due to austerity measures introduced by the university in 2015, budgets for academic staff development activities were slashed. Residential writing 
retreats offered by the Centre for Learning, Teaching and Development (CLTD) were among the first casualties. In 2015, a non-residential retreat was held in a 'no frills' conference venue on campus, as a cost-cutting measure. There was only one facilitator, the author, and there were fewer participants than had been usual in our retreats - nine writers, rather than ten or twelve.

Eight of the nine participants in the writing retreat were mature adults employed as Lecturers or Senior Lecturers in the Faculty of Humanities. The ninth participant was employed as a Senior Lecturer in a professional school of another faculty. All but two of the participants were registered for part-time study, as they were engaged in full-time employment at the university. The traditional model of $\mathrm{PhD}$ students as young, full-time scholars supported by research grants applied to only one of the participants, who held a research grant that allowed her to study full-time.

Eight of the participants were writing specific chapters of their theses or working on journal articles derived from their theses. One participant was developing a conference paper.

The research interests of the participants varied considerably, and were located in disciplines including sports science, music, art history, mathematics, law and sociology.

All nine participants had participated in previous residential writing retreats conducted by CLTD over the years, and all had previously completed an eight-day research writing course in which freewriting and other writing development strategies were introduced.

I asked the nine academics in the retreat to reflect on how they might do things differently, given the opportunity to start their doctoral thesis again. I devised the prompt 'If I were starting my thesis again ...'. 'The participants completed the freewrite by hand in the four minutes allocated for it. They agreed to share their writing by reading it aloud to the group, and took turns to do so. They had the option to pass, if they preferred not to read. None of them exercised this option.

\section{Research design}

I had not decided on freewriting as a focus for research in advance of the retreat. The participants were all current doctoral students or very recently graduated doctoral students; I devised a prompt to stimulate freewriting on a topic they all had in common, to break the ice. The participants took turns to read their freewriting aloud to one another, and I was struck by some of the things they said, as were others at the table. I asked them if I could gather and photocopy their freewrites for research purposes. I gathered their writing with their informed consent, after discussing ethical considerations with them, including the need to disguise their names to protect confidentiality. Anonymity could not be promised within the small group, in 
which the members all knew one another.

In the week after the retreat I typed up each handwritten freewrite separately and sent it to the writer by email, along with a copy of the original handwritten freewrite. I enquired whether the writer wished to make any corrections or adjustments to their text. Some writers made minor changes to words that I had misspelled, misinterpreted or omitted in transcription. I then read, re-read and analysed all nine freewrites to identify key themes in, and characteristics of, the freewrites. I chose three of the nine freewrites to use as case studies because they showed different personal approaches to the task, while illustrating particular features of freewriting. I undertook dialogue and member checks with the three writers by email to strengthen the validity of my interpretation of the data. I asked each writer to approve my analysis of her freewrite.

I attempted to use rich, thick description to convey the context and findings so that the reader would get a sense of shared experience, and to enhance the trustworthiness and credibility of the study (Cresswell 2007). I then reflected on the entire research experience to extract principles and draw conclusions from the freewrites.

\section{RESEARCH FINDINGS}

The first of the three freewrites is by Dee whose text resonates with Elbow's (2000) assertion that freewriting allows voice, energy and presence to emerge.

If I were starting my thesis again ... Oh no! To go back to the start line - was it because I false-started? - wrong! Back to the beginning - but this could be a good thing - a fresh page - to start having learned so many lessons. Perhaps this time I would be prepared - I would be organised - I would approach it so differently.

Thinking back, it would be wonderful to have done the training before starting the ultra-marathon. There wouldn't be so many technical errors - this would certainly improve my performance. Perhaps too my coach + I would have been able to develop a more constructive relationship - I would feel more confident, more prepared, ready to start ....

But I am so far down the track, I need to survive the injuries, the muscle fatigue, the mental anguish - I need to get to the end!!

[overleaf]

If I were writing ...

I would fully understand my proposed research having explored every angle - inside, outside, upside down ....

The race would be run at a slow steady pace, moving one step at a time, without distraction. (Dee)

Dee wrote a dialogue with her inner self which related the 'long haul' of writing a thesis to running a marathon. She pointed to the injuries, fatigue and anguish which characterise long distance running and writing a doctoral thesis; the humiliation of a 'false start'; the unanticipated 'performance' problems arising from lack of knowledge or training. 
Her metaphor of the ultra-marathon is interesting. Readers who have written a doctoral thesis are likely to identify with Dee's remembered pain and frustration. Dee's voice is wry, ironic ... but also hopeful. She quickly rethinks her situation in order to see if there are alternatives to the mortification of a 'false start' ('wrong!' as she says). Hindsight has given her insight. She imagines a 'fresh start', with better planning, preparation and resources.

In a skilful and amusing way, Dee's freewrite communicates her realisation that managing oneself is important- in running a marathon, as in writing a thesis. Developing resilience and pacing oneself is necessary. Maintaining relationships is essential. She picks herself up, dusts herself off, and keeps running (and writing).

Like Dee’s freewriting, Kay’s freewrite is evocative and her voice is distinctive.

If I were starting my thesis again, I would make sure I was ready to do it. I would undertake the
study as a full-time student. I would have a lot more faith in my own ideas and [my] own vision. I
would take a long time to choose the topic and the supervisor/s. I would be more insistent that the
process dimensions followed what I need to be a good researcher and writer. I would dedicate most/
all of my time to my thesis. I would spend much more time than I have been able to do immersed
in the literature and the theory. I would enjoy the process much more and have fun with it. I would
start the formal writing process very early rather than very late. I would be confident with rough
ideas, unformulated ideas and non-ideas rather than waiting for the big idea to develop from
nowhere. I would hope to realise that writing is a struggle and so would begin my conquest from
the beginning with the grace of a novice writer, with ambition and gaining confidence. I would not
allow myself to be whittled away but would hope to grow from strength to strength and I would
most importantly ensure I was trained in discipline and vaccinated from distraction and self-
deprecation. I would find ways to be pleasantly and happily at that desk working every day without
resentment, fear and loathing. I would most of all want the PhD to be everything it has not been:
my friend and love, my dream and my achievement. (Kay)

Kay is someone who has thought long and hard about the debilitating process she has been trapped in. Unlike Dee, Kay's feelings of regret and resentment run so deep that they prevent her from imagining steps she could take to retrieve her situation. The only way to save her thesis and her confidence would be a completely new start.

In her freewrite, Kay contrasts her actual and desired emotional states when writing her thesis. It is a text which reveals bitter disappointment in every aspect of doctoral study, from the amount of time she was able to devote to study, to the poor choice (or allocation) of a supervisor. She has been 'whittled away' by repeated painful experiences. She yearns for the confidence, strength, faith and vision to complete her doctorate. She has a vision of her thesis - her 'friend and love', her 'dream and achievement', but she cannot, at this stage of her studies, summon the confidence, or energy, to bring her dream to fruition. So, her vision of doctoral study is revealed as a delusion, while her labours thus far resemble a nightmare from which she cannot escape. 
In Kay's case, freewriting has released feelings, ideas and thoughts to flow and be gathered. On the one hand, this release allows her to identify the source of her injury and pain, to acknowledge feelings of abandonment and resentment with respect to her thesis and her supervisor(s). On the other hand, it has developed her thinking and creativity, as revealed in the poignant metaphors she gave to the alter ego of her doctoral thesis. Whether she will act on, or adjust, the feelings that have been released remains to be seen.

Anne's freewrite, in the third case study, is remarkably fluent and creative. It is inviting to read. Anne freewrites frequently and derives meaning and pleasure from it. She is interested in what she thinks (Richardson 2000).

If I were writing my thesis again I would write more precisely from the beginning, and I would try to write more creatively, to take more risks with the language and style. A three act play! Imagine that. A novel? I would spend a lot more time working out the structure of the whole at the beginning so that I would avoid the back and forth, back and forth of the fiddling with the structure at the middle and at the end. I would believe I could do it the whole way rather than lose confidence as I have. Show the drafts more often than I have - not be scared to show the messiness of the process because I believe it is an essential part of the process. Would I change my topic? Not sure my topic has not been what I thought it was. I would definitely play more and fret less. Writing with energy and enthusiasm and joy - it's not too late to start writing like this. (Anne)

Freewriting helps Anne to 'get it down' (on the page) so that she can explore her own thoughts and ideas in relation to others'. She is also interested in discovering new strategies for writing and new ways of expressing herself, as an artist, a writer and a researcher. The freewrite captures her belief that writing should be an integral, and creative, aspect of research.

Anne plays with the possibility of injecting more creativity, more confidence and more risktaking in her writing, implying that she is motivated to change aspects of her writing, and that she is aware that she can, through writing, reap rewards of pleasure. She recognises the messiness of the creative process as an essential part of writing, and counsels herself about steps that she could take to avoid the struggle with structure (the 'back and forth, back and forth' that she experienced while 'fiddling with the structure' of her thesis). She ends on a positive note: it's not too late to start writing 'like this' - with energy and enthusiasm and joy. Her freewrite expresses Anne's acceptance that becoming temporarily 'lost', or losing track, is part of a creative process and part of discovering oneself, in writing, as in other artistic endeavours (Cameron 1995; Badenhorst 2008).

\section{REFLECTION AND DISCUSSION OF THE RESEARCH FINDINGS}

The three freewrites above were chosen for the way they exemplify the voice, energy and presence of the writer, which Elbow (2000) announced as a benefit, or outcome, of freewriting. 
In addition, the freewrites show that tacit knowledge, previous knowledge and experiential knowledge, in this case of doctoral study, can be harnessed usefully in freewriting. They also show that aspects of personal identity and emotion are released in freewriting; aspects which might not be revealed in a doctoral thesis or journal article.

The freewriting prompt, 'If I were writing my thesis again ...' elicited creative, imaginative responses from the three writers. Hindsight is a way of reflecting back on experience and also a way of consoling oneself. Hindsight allows the writer to recognise alternative ways of feeling, thinking, writing and being (about the topic, supervisor, writing, and processes that take place during doctoral study). Freewriting allows these alternative ways of being and doing to be captured on the page, and to be shared with and appreciated by others.

The freewrites amplify Burford’s (2014) call for more attention to be given to emotion and context of doctoral study, and Mouton et al.'s (2015) view that doctoral students are not adequately equipped and supported by their institutions to produce good work in the high pressure context of higher education in South Africa. A writing retreat, especially one which incorporates strategies and processes to encourage writers to try out new ways of thinking and writing, and to share their views and experiences of writing with one another, can greatly enhance writers’ ability to write generatively and with pleasure and confidence.

The desire to develop a sense of agency and identity as a writer and researcher was a feature of the three freewrites presented in this article. The wealth of ideas, and the diversity of voices produced in the freewrites, is testimony to the capacity of freewriting to generate ideas and text, mobilise different kinds of knowledge, and develop writers' confidence and creativity.

\section{ACKNOWLEDGEMENTS}

This article was written in a generative and enjoyable writing retreat held in the Western Cape, South Africa, supported by funding from the Department of Higher Education's National Collaborative Teaching Development Grant for improving teaching and learning in South African universities. I wish to thank the two anonymous reviewers who commented on an earlier draft of this article, as well as my Wits colleagues, Sue Benvenuti and Moyra Keane, who always contribute ideas, encouragement and laughter to writing endeavours. Most of all, I thank Anne, Dee and Kay for allowing their freewrites to be revealed and analysed in this article.

\section{REFERENCES}

Badenhorst, C. 2007. Research writing: Breaking the barriers. Pretoria: Van Schaik.

Badenhorst, C. 2008. Dissertation writing: A research journey. Pretoria: Van Schaik. 
Badenhorst, C., C. Moloney, J. Dyer, J. Rosales and M. Murray. 2015. Thinking creatively about research writing. In Working with academic literacies: Research, theory, design, ed. T. Lillis, K. Harrington, M. Lea and S. Mitchell, 227-254. South Carolina: WAC Clearinghouse/Parlor Press.

Benvenuti, S., J. Castle and M. Keane. 2013. Writing retreats in response to the 'incessant demands' of the university. Paper presented at the $4^{\text {th }}$ World Conference on Learning, Teaching and Educational Leadership. Published online in Procedia - Social and Behavioural Sciences 000-000 www.sciencedirect.com/

Burford, J. 2014. Doctoral writing as an affective practice: Keep calm and carry on? In Pushing boundaries in postgraduate supervision, ed. E. Bitzer, L. R. Albertyn, L. Frick, B. Grant and F. Kelley, 69-84. Stellenbosch: SUN Press.

Cameron, J. 1995. The artist's way. London: Pan Macmillan.

Castle, J. and M. Keane. 2016a. Retreating to write: Are publications the only important outcome? Alternation 23(1): 265-284.

Castle, J. and M. Keane. 2016b. 'It was an oasis in a busy life, a busy city': The Centre for Learning, Teaching and Development (CLTD) writing retreat. Journal of Education 66: 207-225.

Cresswell, J. 2007. Qualitative enquiry and research design. 2nd Edition. Thousand Oaks, London and New Delhi: Sage Publications.

Elbow, P. 2000. Everyone can write. New York and Oxford: Oxford University Press.

Goldberg, N. 1986. Writing down the bones. Freeing the writer within. Boston and London: Shambhala.

Grant, B. 2006. Writing in the company of other women: Exceeding the boundaries. Studies in Higher Education 31(4): 483-495.

Harrison, L. 2011. PaperHeaDs: Living doctoral study, developing doctoral identity. Bern: Peter Lang.

Kamler, B. 2001. Relocating the personal: A critical writing pedagogy. Norwood, SA: Australian Association for the Teaching of English.

Mouton, J., N. Boshoff and M. James. 2015. A survey of doctoral supervisors in South Africa. South African Journal of Higher Education 29(2): 1-22.

Murray, R. 2009. Writing for academic journals. $2^{\text {nd }}$ Edition. Maidenhead Bks and New York: Open University Press and McGraw Hill.

Murray, R. 2013. Writing for academic journals. Maidenhead and New York: Open University Press.

Murray, R. and S. Moore. 2006. The handbook of research writing: A fresh approach. New York: McGraw Hill and Open University Press.

Richardson, L. 1998. Writing: A method of inquiry. In Handbook of qualitative research, ed. N. K. Denzin and Y. S. Lincoln, 345-371. Thousand Oaks, CA: Sage.

Richardson, L. 2000. New writing practices in qualitative research. Sociology of Sport Journal 17: 520.

Street, B. 1984. Literacy in theory and practice. Cambridge: Cambridge University Press. 